\title{
Polymer Dispersions from Catalytic Polymerization in Aqueous Systems
}

\author{
STEFAN MECKING \\ Chair of Chemical Materials Science; Department of Chemistry; University of Konstanz; \\ Universitätsstr. 10; 78457 Konstanz; Germany \\ E-mail: stefan.mecking@uni-konstanz.de \\ Tel.: +49(0)7531 88-5151 \\ Fax: $+49(0) 753188-5152$
}

\begin{abstract}
By contrast to traditional free radical emulsion polymerization, catalytic polymerization allows for polymer microstructure control. In terms of monomers polymerizable, both techniques are largely complementary. Since the beginning of this decade, an increasing number of reports on polyolefin, polybutadiene, polyalkenamer, polynorbornene, polyketone and polyacetylene dispersions prepared by catalytic polymerization in disperse aqueous systems has appeared. This contribution reviews the preparation of these dispersions, their colloidal properties, particle formation mechanisms, particle morphologies and polymer microstructures.
\end{abstract}

\section{Introduction}

Emulsion polymerization is amongst the most important and versatile polymerization processes. ${ }^{1-6}$ Beyond the specific advantages of the polymerization process, emulsion polymerization provides access to polymer latexes. 10 million tons of polymer latexes are used annually for a variety of applications, such as coatings and paints. A key step in most applications is film formation upon evaporation of the dispersing medium, rendering aqueous dispersions particularly environmentally benign. At the same time, polymerizations in disperse systems and polymer dispersions are also the object of broad fundamental studies concerned with particle formation processes, the structure of particles and its control, and structure formation from dispersions. ${ }^{1,5-8}$

The industrial synthesis of polymer dispersions by emulsion polymerization employs freeradical polymerization exclusively. The control of polymer microstructures is very limited in these traditional radical polymerizations. Controlled radical polymerization techniques, such as stable free radical polymerization, atom transfer radical polymerization (ATRP), or reversible addition fragmentation transfer polymerization (RAFT) can allow for the synthesis of polymers with narrow molecular weight distributions or block copolymers. Controlled free radical techniques are also applicable in aqueous emulsions to afford polymer dispersions. ${ }^{9-14}$ Polymerization methods other than free radical polymerization, namely polycondensation/polyaddition and ionic polymerizations, have also been studied in aqueous systems as a route to polymer dispersions. ${ }^{15-17}$ Polyurethane dispersions are prepared commercially as secondary dispersions or by polycondensation or polyaddition of prepolymers in aqueous systems. $^{2,18}$ 
Of all polymerization methods, without doubt catalytic polymerization offers the broadest scope of microstructure control. Particularly, stereoregularity of polymers, and the composition of copolymers can be controlled. Living polymerizations and synthesis of block copolymers are also possible. ${ }^{19-22}$ In terms of the monomers polymerizable, catalytic polymerization is largely complementary to the aforementioned polymerization techniques.

The Ziegler catalysts employed industrially for the polymerization of olefins and dienes are highly water-sensitive. They are based on early transition metal centers (termed 'early' according to their position on the left side of the d-block in the periodic table of the elements), such as $\mathrm{Ti}, \mathrm{Zr}, \mathrm{Cr}$ and $\mathrm{V}$, which are very oxophilic and reactive towards water. This hampers utilization in aqueous emulsions (a suspension-type polymerization of styrene to syndiotactic polystyrene by a metallocene catalyst, which required a pre-polymerization in the absence of water prior to emulsification in order to encapsulate the catalyst in the polymer formed, has been reported $\left.{ }^{23,24}\right)$. By comparison, late transition metals like $\mathrm{Ru}, \mathrm{Co}, \mathrm{Rh}, \mathrm{Ni}$ and $\mathrm{Pd}$ are much

less oxophilic. ${ }^{25-27}$ They can be employed for polymerizations in aqueous systems. ${ }^{14,28-30}$ Under appropriate conditions, the polymer formed can be obtained in the form of a colloidally stable dispersion.

In the last few years, an increasing number of reports on catalytic polymerization in aqueous systems affording polymer latexes has appeared. This review focusses on the synthesis of aqueous polymer dispersions and their properties. Catalyst synthesis and design, molecular mechanisms of polymerization and catalyst activation and deactivation specific to aqueous systems, ${ }^{31-36}$ and catalytic polymerizations in aqueous systems in general are not considered. The latter issue has been reviewed. ${ }^{14,28-30,37}$

\section{General methodology and considerations}

In free radical polymerization, the terms emulsion polymerization, suspension polymerization, dispersion polymerization, and miniemulsion polymerization can be defined on the basis of different criteria. The initial state of the reaction mixture (solubility or insolubility of monomer and initiator, respectively, in water; presence or absence of surfactant; droplet sizes), the resulting particle sizes, or particle formation mechanisms can be considered. ${ }^{1,4-6,38-40}$ As the molecular mechanisms of chain initiation, growth, and termination and transfer are entirely different in catalytic vs. emulsion polymerization, and in some cases specific techniques are used to disperse the (pre)catalyst, the aforementioned terms can not always be transferred unambiguously to catalytic polymerizations. The term 'catalytic polymerization in emulsion' has been used to indicate that a catalytic polymerization is carried out in a disperse aqueous system containing surface-active agents, without specification of the colloidal mechanisms of polymerization or the final colloidal state of the reaction mixture.

The term 'precatalyst' refers to the compound introduced to the reaction, which under reaction conditions forms the actual catalyst, that is the active species. The precatalyst can be an isolated well-defined metal complex (cf. Scheme 1), or it can be formed 'in situ' from appropriate reagents.

By contrast to the continuous formation and termination of radicals in traditional emulsion polymerization, in catalytic polymerization an active site should ideally exist over the entire polymerization experiment. Catalyst stability, specifically towards deactivation by water, is therefore an issue.

The productivity of a catalyst can be expressed as turnovers (TO), that is moles of substrate converted to polymer per mole of metal present in the reaction mixture. This enables a com- 
parison of polymerizations involving different monomers and metals (with different molecular weights). Catalyst activity correspondingly can be expressed as TO per time unit.

In very general terms, one obvious prerequisite for formation of a polymer dispersion is that a sufficiently large number of primary particles is nucleated such that the final particles can be sufficiently small to be colloidally stable (generally on the order of $<1 \mu \mathrm{m}$ ). In classical freeradical emulsion polymerization, this is achieved by use of a water-soluble intitiator. Most literature known polymerization catalysts, however, are lipophilic and water-insoluble. Also, although there are exceptions, the preparation of water soluble catalysts usually requires more synthetic effort. For these reasons many studies have employed water-insoluble (pre)catalysts. The precatalyst is finely dispersed in the reaction medium in the form of an aqueous miniemulsion (or microemulsion) of a solution of the precatalyst in an organic phase, that is a small amount of organic solvent or the liquid monomer. In the latter case, care must be taken that the polymerization does not occur during preparation of the miniemulsion already, which would likely result in coagulation under the high shear of the miniemulsification process and also hamper the formation of sufficiently small droplets. In free-radical miniemulsion polymerization with water-insoluble initiators, this is usually accomplished by employing initiators which decompose with notable rates only at elevated temperatures. Polymerization only starts upon heating the monomer miniemulsion. For many catalysts, however, polymerization will occur with signficant rates at room temperature already. In this case, the catalyst can be dispersed as a miniemulsion of a catalyst solution in a small amount of an inert organic solvent, and added to the monomer which is in the form of a macroemulsion, miniemulsion or microemulsion. An alternative is that a lipophilic precatalyst, which only becomes active in the presence of an additional activator, is mini- or microemulsified as a solution in the monomer. Polymerization is started by addition of an activator to the aqueous phase, which has to be water-soluble to a certain extent. In summary, a major motivation for employing miniemulsions is to generate a high degree of dispersion of a water-insoluble (pre)catalyst. ${ }^{41}$

Sodium dodecyl sulfate (SDS) has proven to be sufficient in many cases for stabilization of the final particles. Much of the work reviewed has been restricted to SDS, and the surfactant was not further varied or optimized in terms of colloidal stability, solids contents achievable or the like.

For the sake of clarity, to differentiate a conventional emulsion from a mini- or microemulsion, the former are also termed as macroemulsions were appropriate in the following.

\section{Polyolefin dispersions}

For the synthesis of polyethylene dispersions, neutral nickel(II) catalysts have proven to be useful. Two specific types of catalyst system have emerged for ethylene polymerization in aqueous systems, nickel(II)phosphinoenolato complexes ${ }^{42-47}$ (1) and nickel(II) salicylaldiminato complexes ${ }^{44,48-51}(\mathbf{2})$. Both types of catalysts had originally been developed for non-aqueous polymerizations. ${ }^{26,27,52-58}$ They differ in the chelating ligand, which stays bound to the metal center throughout the polymerization reaction, and controls the catalytic properties of the active metal site. Examples of two compounds, which can be used as precatalysts, are depicted in Scheme 1. In the active species, the ligand $\mathrm{L}$ (e.g. $\mathrm{L}=$ amine, pyridine, or phosphine) is displaced by the monomer. The metal bound alkyl or aryl group has the function of starting chain growth. Migratory insertion of monomer into the metal-alkyl bond is the first step of chain growth (Scheme 1). 

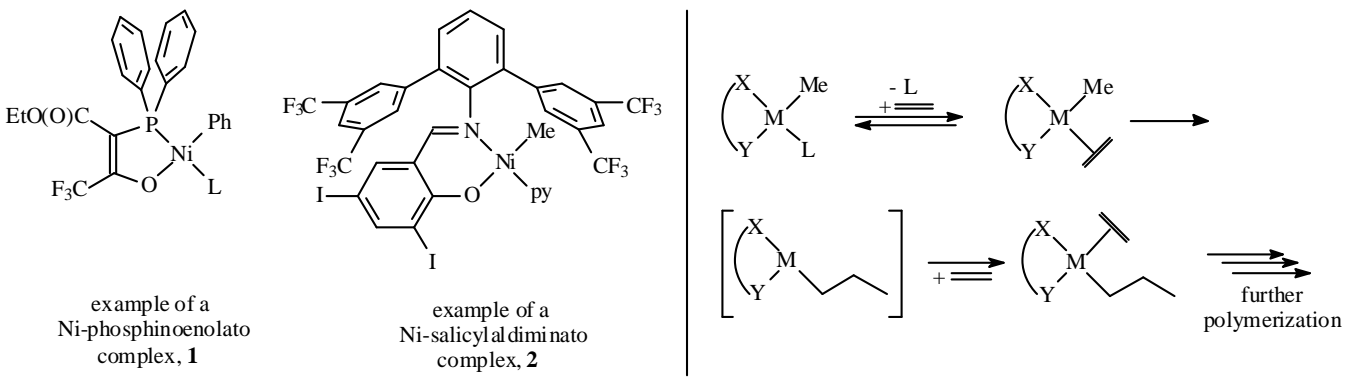

Scheme 1. Precatalysts for ethylene polymerization in aqueous systems and activation for polymerization.

The salicylaldiminato complexes (2) are more versatile in terms of the molecular weight range accessible $\left(\mathrm{M}_{\mathrm{n}}\right.$ up to several $\left.10^{5} \mathrm{~g} \mathrm{~mol}^{-1}\right)$ and control of polymer crystallinities. The modular synthesis of the ligands allows for systematic variations of the catalyst structure, and correspondingly of the catalytic properties. Phosphinoenolato complexes (1) polymerize ethylene to low-molecular-weight $\left(\mathrm{M}_{\mathrm{n}}<10^{4} \mathrm{~g} \mathrm{~mol}^{-1}\right)$ linear polyethylene which is semicrystalline. Advantageous features of this type of catalyst is their robustness and, in some cases, high catalytic activity or easy accessibility.
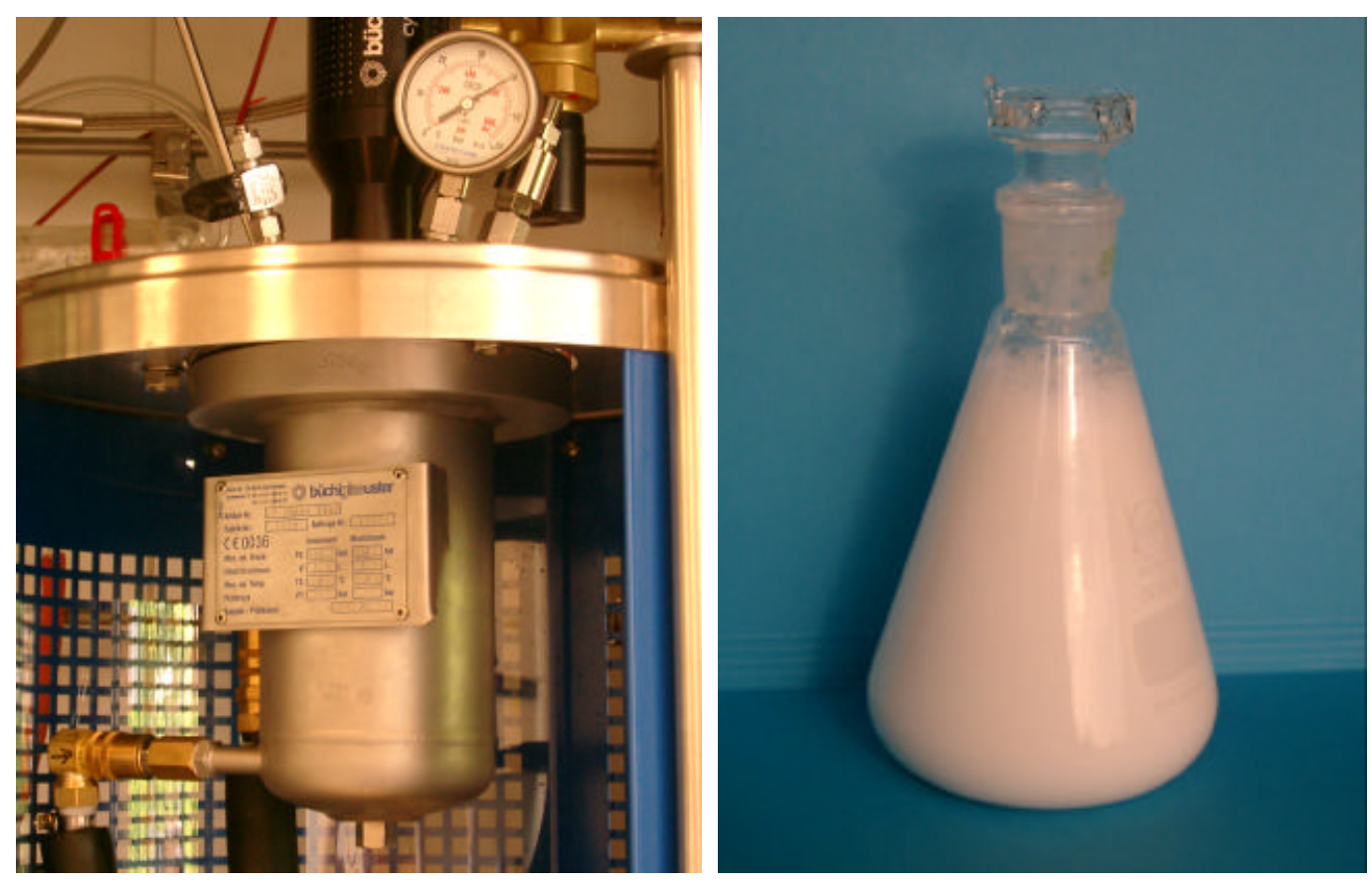

Figure 1. Reactor utilized for catalytic emulsion polymerization (left) and polyethylene dispersion prepared (right; $0.5 \mathrm{~L}$ of dispersion with $10 \%$ solids content, $\mathrm{M}_{\mathrm{n}} 10^{5} \mathrm{~g} \mathrm{~mol}^{-1} ; \mathrm{M}_{\mathrm{w}} / \mathrm{M}_{\mathrm{n}} 2.5 ; \mathrm{T}_{\mathrm{m}} 125^{\circ} \mathrm{C}$; catalyst productivity in dispersion synthesis $3 \times 10^{4}$ TO over $2 \mathrm{~h}$ ).

Most often, water-insoluble catalysts have been employed. They were introduced to the reaction mixture as a miniemulsion of a solution of the catalyst in a small amount of toluene, or also in the liquid comonomer in the case of copolymerizations. Standard glass or steel reactors with appropriate mechanical stirrers are utilized (Figure 1). Typical reaction conditions are 10 to 40 atm ethylene pressure, and $25{ }^{\circ} \mathrm{C}$ to $80{ }^{\circ} \mathrm{C}$. Note that ethylene does not form a separate liquid phase under these conditions. The average particle sizes of the dispersions obtained by 
this procedure are typically in the range from 100 to $500 \mathrm{~nm}{ }^{45-49,63}$ The preparation of dispersions with solids contents of up to $30 \%$ has been reported. ${ }^{46,47}$

Catalyst activities of up to $1.7 \times 10^{5} \mathrm{TO} \mathrm{h}^{-1}$ have been published to date for the preparation of polyethylene dispersions. ${ }^{45}$ This corresponds to an overall productivity over the entire polymerization experiment of $10^{5} \mathrm{TO}$, that is $50 \mathrm{~kg}$ polyethylene per $\mathrm{g} \mathrm{Ni}$. For a typical dispersion of $10 \%$ solids content, this corresponds to $2 \mathrm{ppm} \mathrm{Ni}$ in the final dispersion.

Polymer crystallinities are decisive for film formation from dispersions. For traditional film formation from polymer dispersions, as utilized in coatings and paints, polymers of relatively low crystallinity or amorphous polymers are required. Polymerization with the late transition metal complexes employed in aqueous systems differs from traditional polymerization with Ziegler catalysts or metallocenes. As with Ziegler catalysts, ethylene can be homopolymerized to linear polyethylene, but highly branched ethylene homopolymers can also be obtained. This is due to a more or less pronounced propensity of the active sites to 'chain walk' along the growing polymer chain (vide infra, Scheme 3 illustrates chain walking for a 1-olefin). ${ }^{59,60-}$ ${ }^{61}$ The branching, and thus crystallinity of ethylene homopolymers can be controlled via the catalyst. Depending on the remote substituents $\mathrm{R}$ (Scheme 1, depicted example for complexes of type $2, \mathrm{R}=\mathrm{CF}_{3}$ in this case) and to a lesser extent the reaction temperature, the entire range from linear semicrystalline polyethylene ( 5 branches / 1000 carbon atoms; crystallinity from DSC ca. $65 \% ; \mathrm{T}_{\mathrm{m}}$ ca. $127{ }^{\circ} \mathrm{C} ; \mathrm{M}_{\mathrm{n}}>10^{4} \mathrm{~g} \mathrm{~mol}^{-1}$ ) to highly branched amorphous material (80 branches / 1000 carbon atoms; $\mathrm{M}_{\mathrm{h}} 2 \times 10^{3} \mathrm{~g} \mathrm{~mol}^{-1}$ ) is obtained. ${ }^{50,51}$ The increase in branching goes along with a reduction in molecular weight, as both branch formation and chain transfer occur via $\beta$-hydride transfer as the underlying step.

An alternative for crystallinity control is introduction of branches by copolymerization. Dispersions of ethylene copolymers with 1-olefins ranging from 1-butene to 1-hexadecene, with $\alpha, \omega$-dienes, and even with the functionalized comonomers undec-10-enol or undec-10-enoic acid esters have been prepared. ${ }^{46,47,62,63}$ Incorporation of comonomer reduces polymerization rates to some extent depending on the catalyst, and in some cases also molecular weights. For catalysts of type 1, low-molecular weight materials are obtained as in ethylene homopolymerization $\left(\mathrm{M}_{\mathrm{n}}=2 \times 10^{3} \mathrm{~g} \mathrm{~mol}^{-1}\right){ }^{46,47}$ With catalysts of type 2 , ethylene/1-butene and ethylene/norbornene copolymer dispersions with $\mathrm{M}_{1} 1$ to $2 \times 10^{4} \mathrm{~g} \mathrm{~mol}^{-1}$ were obtained. Due to a high selectivity of the $\mathrm{Ni}$ (II) catalysts for ethylene, incorporation of ethylene is preferred over 1-olefin comonomer incorporation. The ratio of comonomer molar ratio in the organic phase, $\mathrm{x}_{1 \text {-olefin }}$, vs. molar ratio incorporated in the polymer, $\mathrm{X}_{1 \text {-olefin }}$, is typically $\mathrm{X}_{1 \text {-olefin }} / \mathrm{x}_{1 \text {-olefin }} \sim 0.05$. Norbornene as a (readily available) strained cyclic olefin is incorporated better, $\mathrm{X}_{\text {norbornene }} / \mathrm{X}_{\text {norbornene }} \sim 0.25$ as studied for catalysts of type $2 .{ }^{63}$ However, incorporation of comonomer is aided in the aqueous system by comparison to non-aqueous polymerization in organic solvents by the compartmentalization of the former, resulting in a relatively high comonomer concentration in the organic phase (that is, initial miniemulsion droplets containing the catalyst, and polymer particles formed). ${ }^{46,63}$ Albeit in most examples comonomer conversion was incomplete, complete conversion can also be achieved. Dispersions of ethylene copolymers with up to 6 mol- $\%$ or $15 \mathrm{wt} .-\%$ incorporated 1-olefin, or 6 mol- $\%$ (20 wt.$\%)$ norbornene were reported. In linear ethylene/1-olefin copolymers, this reduced the crystallinity down to ca. $30 \%$ (determined by DSC on the bulk polymer). Norbornene as a comonomer reduces crystallinity more effectively. At the same time, the $\mathrm{T}_{\mathrm{g}}$ (which increases with norbornene content) ${ }^{64}$ remains below room temperature. At 3 mol- $\%$ norbornene content of the copolymer partial coalescence of particles is observed in TEM samples, and at 6 mol- $\%$ 
a continuous film is observed by TEM (Figure 2). Tough transparent films are obtained upon evaporation of water from the dispersions.

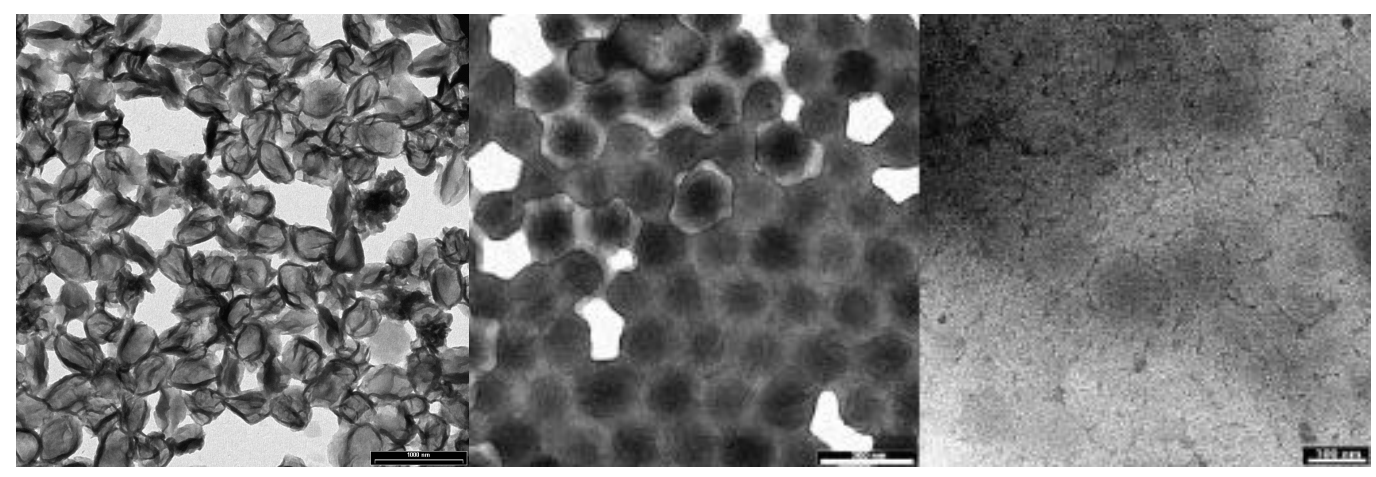

Figure 2. TEM micrographs of ethylene-norbornene copolymer dispersions. Left: Ethylene homopolymer for comparison. Middle: $X_{\text {norbornene }} 3$ mol- $\%$. Right: $X_{\text {norbornene }} 6$ mol-\% (scale bars: left image: $1 \mu \mathrm{m}$; middle: 200 $\mathrm{nm}$; right: $100 \mathrm{~nm}$ ). Reproduced with permission from [63]. Copyright 2006 American Chemical Society.

Studies of the number of final particles vs. the number of initial precatalyst-containing toluene miniemulsion droplets in ethylene homopolymerization indicate that the number of final particles is ca. 20 fold higher. A possible explanation is that due to the high crystallinity of the linear polyethylene formed in this study and its low miscibility with toluene, the polymer rapidly precipitates to form new particles which exit the droplets. ${ }^{45}$ By contrast, in ethylene/1olefin copolymerization affording less crystalline polymer, the number of miniemulsion droplets and of final particles was approximately the same. This indicates that an initial miniemulsion droplet, containing comonomer and dissolved catalyst, is polymerized to a particle. ${ }^{46}$ Another conclusion was that polymerization is limited by swelling of polymer particles with toluene, to a polymer weight fraction of 0.5 in the final particles. This (fortunately) is not a general principle, in other studies the amounts of organic solvents were much lower than the amount of polymer formed, or no organic solvents were present at all (vide infra).

Studies of the morphology of latex particles of linear polyethylene by TEM and AFM reveal that the particles consist of stacked lamella of ca. $10 \mathrm{~nm}$ thickness. This results in a nonspherical lentil-like outer shape. In addition to these multilamella particles, a signficant portion of the particles consist of only a single lamella (Figure 3). ${ }^{65}$

Studying crystallization in the dispersions by DSC, remarkably high supercoolings of ca. 45 ${ }^{\circ} \mathrm{C}$ degrees are observed (Figure 4). ${ }^{65}$ In bulk polyethylene samples, heterogeneous nucleation occurs exclusively, and a few nuclei are sufficient to induce crystallization of a comparatively large sample. However, in the polymer dispersion, the submicron droplets crystallize independently from one another. This phenomenon ${ }^{66,67}$ is particularly pronounced for these highly crystalline particles. The large supercoolings observed match with the highest supercoolings reported to date for polyethylene crystallization, ${ }^{68-71}$ such that nucleation can be considered to occur in a homogeneous fashion. 


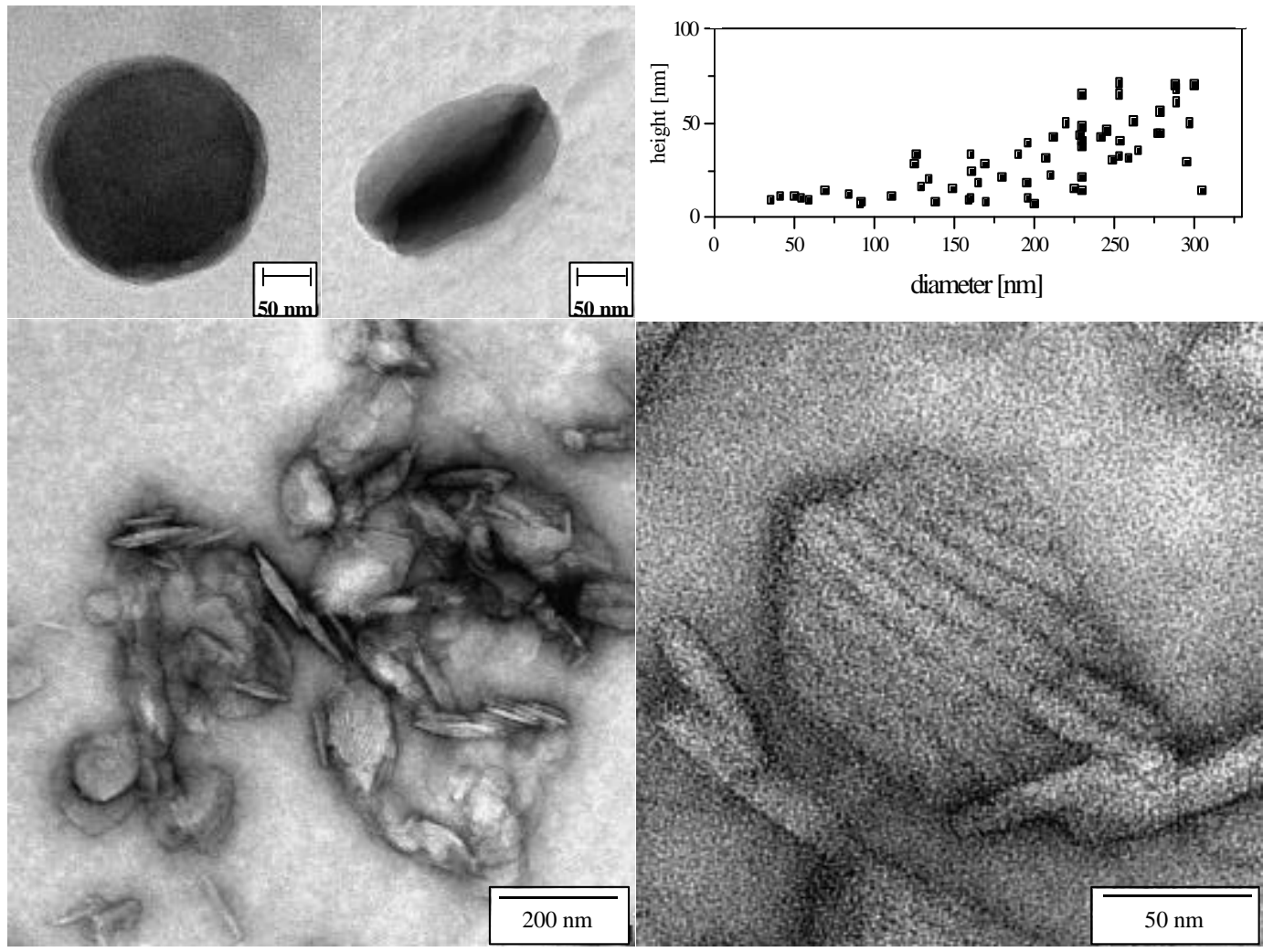

Figure 3. TEM micrographs and AFM data for latex particles of linear polyethylene $\left(\mathrm{M}_{\mathrm{n}} 2-3 \times 10^{3} \mathrm{~g} \mathrm{~mol}^{-1}\right.$, crystallinity of bulk polymer from DSC $72-80 \%$ ). Upper left and middle: individual particle, and same particle tilted by $60^{\circ}$. Upper right: AFM data for a number of particles. Lower left: microtome cut of resin-embedded particles, showing the lamella structure and single lamella particles. Right: selected multilamella particle (stained with $\mathrm{RuO}_{4}$ ). Reproduced with permission from [65]. Copyright 2003 American Chemical Society.

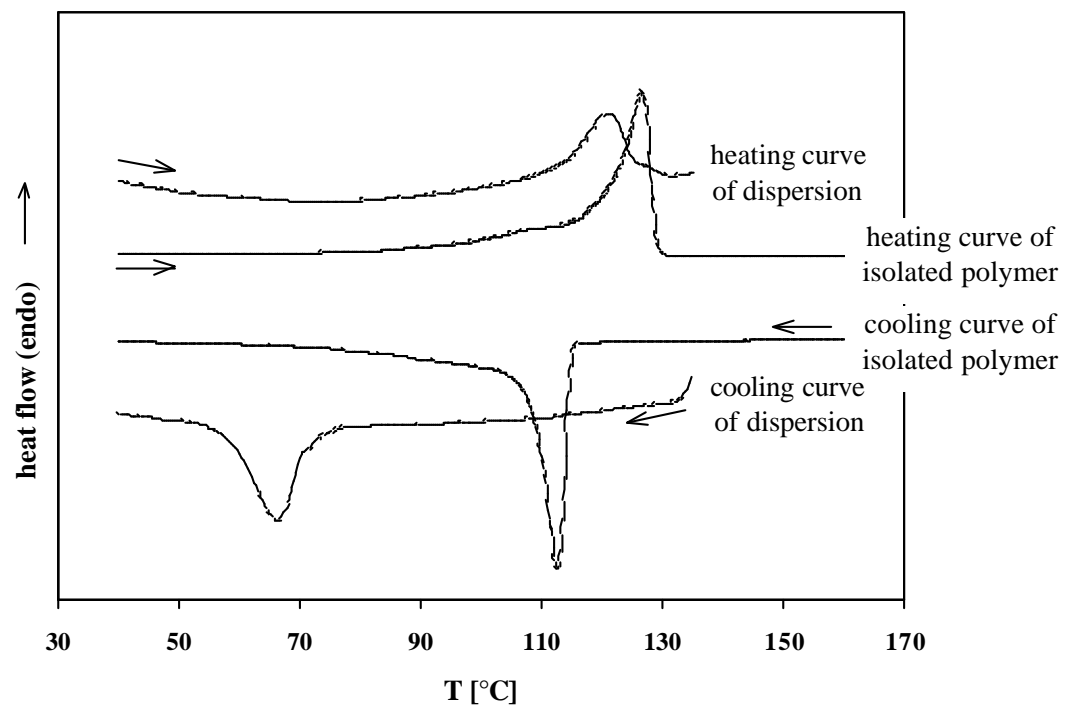

Figure 4. DSC traces of a polyethylene dispersion and of isolated bulk polymer for comparison (heating / cooling rate $10 \mathrm{~K} \mathrm{~min}^{-1}$ ). Reproduced with permission from [65]. Copyright 2003 American Chemical Society.

The preparation of particles smaller than $30 \mathrm{~nm}$ is an attractive challenge for any given polymerization technique and polymer microstructure. Free radical polymerization of monomer microemulsions can afford polymer particles of only $10 \mathrm{~nm}$ size. ${ }^{72-74}$ This has been 
demonstrated for a number of monomers such as styrene or acrylates $(\mathrm{o} / \mathrm{w})$ or acrylamide (w/o). Catalytic polymerization provides access to unusually small polyethylene particles of < $30 \mathrm{~nm}$ size by various routes. ${ }^{75-78}$ Water-insoluble catalysts can be dispersed as a microemulsion of a toluene solution of the precatalyst (1 or $\mathbf{2}$ ), which is subjected to ethylene pressure. Colloidally stable dispersions of particles as small as $10 \mathrm{~nm}$, as determined by dynamic light scattering (DLS; $173^{\circ}$ backscattering) are formed. ${ }^{77}$ From the direct preparation from a microemulsion, the dispersions usually contain a relatively large amount of surfactant, which can however be removed by dialysis to a large extent without changes in particle size to afford dispersions which contain no free surfactant micelles. This microemulsion technique is a rather general method for the synthesis of very small particles by catalytic polymerization, as illustrated by synthesis also of syndiotactic 1,2-polybutadiene dispersions and polyalkenamer dispersions (vide infra).

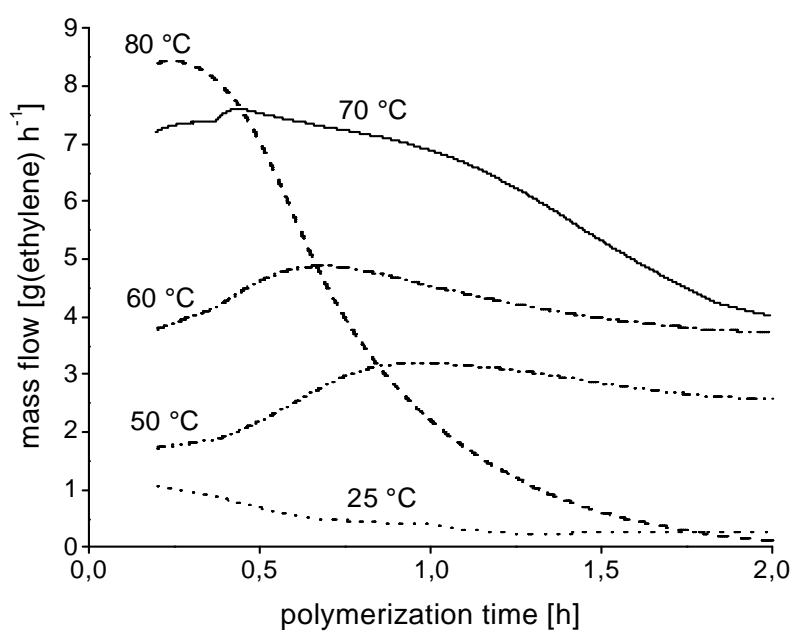

Figure 5. Catalyst stability over time and temperature dependance of polymerization rate in ethylene polymerization by a water-soluble in situ prepared catalyst of type $\mathbf{1}$. Reproduced with permission from $[75,76]$. Copyright 2005 Wiley-VCH.

An aqueous surfactant solution of a water-soluble catalyst of type 1, prepared in situ, polymerizes ethylene to dispersions in the absence of any water-immiscible organic solvent phase. ${ }^{75,76}$ The robustness of the catalyst under aqueous conditions is evident from the ethylene consumption over time (Figure 5). Dispersions with polymer solids contents of $15 \%$ were obtained without optimization. As expected for the catalyst type used, linear lowmolecular-weight polyethylene is formed. The latexes consist of small particles of ca. $20 \mathrm{~nm}$ volume average size (from DLS). The high particle number indicates that a very effective particle nucleation and stabilization must occur. To this end, polymerization with isolated complexes as well-defined precatalysts was studied. Complexes $\left[\left(\mathrm{N}^{\wedge} \mathrm{O}\right) \mathrm{NiMe}(\mathrm{L})\right]$, which are water-soluble due to sulfonated moities or poly(ethylene glycole) groups in the labile ligand $\mathrm{L}$ (cf. Scheme 1), polymerize ethylene to dispersions of particles as small as $4 \mathrm{~nm}$ according to DLS. ${ }^{78}$ Though the single angle DLS utilized is subject to substantial error in this size regime, it is obvious that theses small sizes are at the lower end of known lamella sizes, that is the lowest hierarchical structures responsible for crystallinity in polyethylene. ${ }^{79-81}$ AFM studies suggest these particles to consist of a single crystalline lamella (Tong and Mecking, unpublished results). This is also confirmed by SAXS studies (Weber, Ballauff and Krausch et al., unpublished results). For the particular precatalysts used, an enhanced activation occurs in the aqueous system due to its compartmentalization: the actives species is water-insoluble and 
located in the polymer particles formed, whereas the water-soluble ligand $\mathrm{L}$ will be located in the aqueous phase (Scheme 2). This results in an enhancement of the dissociation of L, which is a prerequiste for polymerization to occur. ${ }^{78}$
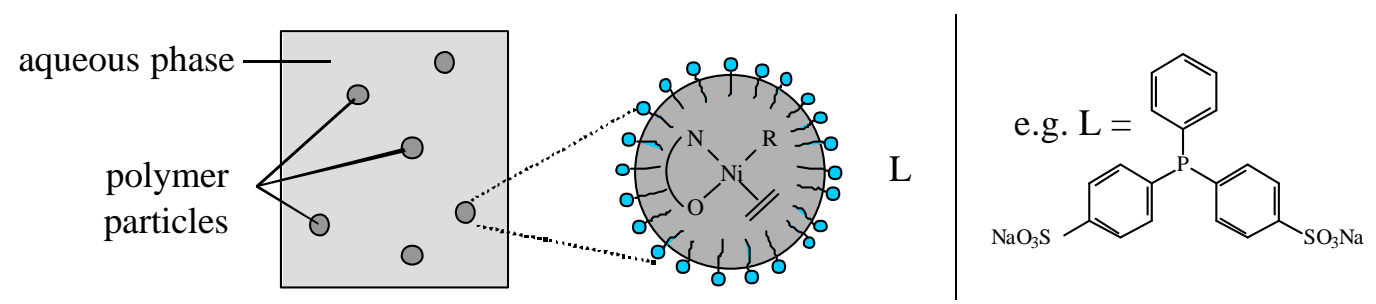

Scheme 2. Enhanced dissociation of the ligand L (which stabilizes the precatalyst, cf. Scheme 1, and renders it water soluble) in favor of formation of the active species by compartmentalization of the lipophilic active species in the particles and of the ligand $\mathrm{L}$ into the aqueous phase.

An estimation of the number of particles generated per nickel center present in the reaction mixture yields values of $N_{\text {part }} / \mathrm{Ni}$ of 0.2 to 10 . The molecular weight distributions $\left(M_{w} / M_{n}\right.$ ca. $2 ; \mathrm{M}_{\mathrm{w}} 6 \times 10^{4}$ to $4 \times 10^{5} \mathrm{~g} \mathrm{~mol}^{-1}$ ) clearly show that chain transfer occurs. Calculated numbers of chains formed per nickel center present in the reaction mixture of, in some cases, $\mathrm{N}_{\text {chain }} / \mathrm{Ni}<1$ thus indicate that not all nickel centers are active. With this in mind, the aforementioned $\mathrm{N}_{\text {part }} / \mathrm{Ni}$ rather indicate that one or several particles are formed per active site. The latter would imply that an active site can leave an existing particle by recoordination of water-soluble $\mathrm{L}$, and nucleate a new particle. In any case, the data demonstrates that a single active site can nucleate and grow a given polymer particle. ${ }^{78}$ This represents a quite unusual particle formation mechanism.

Polymerization of propylene, 1-butene, or 1-hexene by neutral nickel(II) catalysts afforded low-molecular-weight polymers $\left(\mathrm{M}_{\mathrm{n}}\right.$ ca. $\left.10^{3} \mathrm{~g} \mathrm{~mol}^{-1}\right)$ with $\mathrm{T}_{\mathrm{g}} \mathrm{s}$ of -56 to $-77{ }^{\circ} \mathrm{C}$ as a polymer dispersion. ${ }^{82}$ The reaction was carried out as a miniemulsion polymerization, that is a solution of the precatalyst in the monomer was miniemulsified in water by ultrasonication. Dispersions of $3 \%$ polymer solids content with volume average particle sizes of 50 to $100 \mathrm{~nm}$ were obtained. The polymerization reaction is rather slow due to a slow chain growth with the 1olefins. In addition to the common 1,2-enchainment, the polymers also contain 2, $\omega$ - and 1, $\omega$ enchained repeat units (Scheme 3). 2, $\omega$-insertion results in one methyl branch per incorporated monomer unit, irrespective of the 1-olefin used. 1, $\omega$-insertion results in generation of a straight chain segment, akin to linear polyethylene.

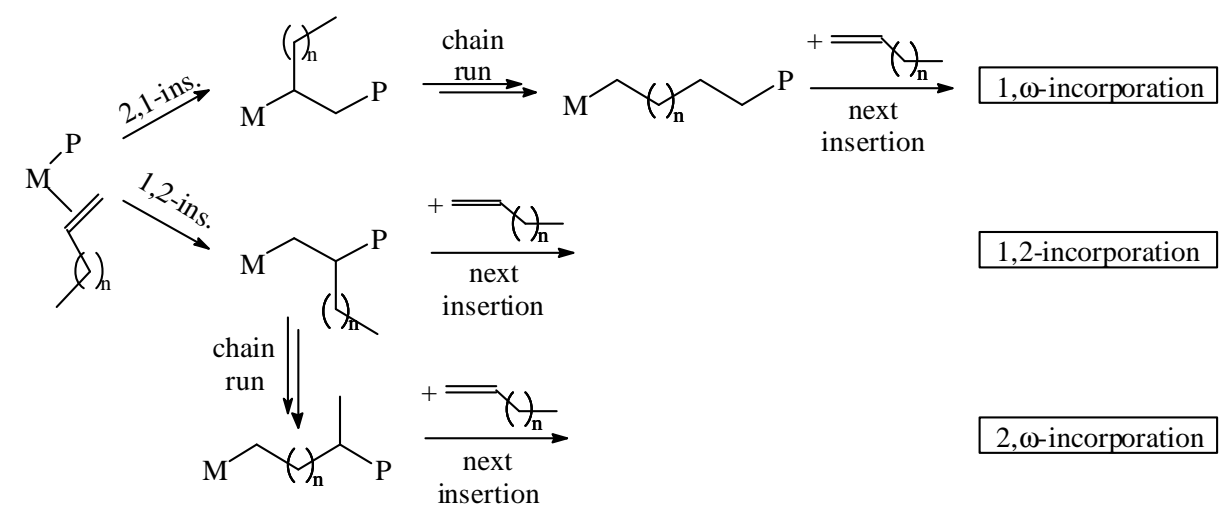

Scheme 3. Modes of incorporation in 1-olefin polymerization. 
Though strictly not in the scope of this review, it is worth noting that the suspension-type polymerization of 1-hexene and 1-octene has been studied. Lipophilic cationic palladium complexes were employed, which have a strong propensity for chain walking. Thus, substantial 1, $\omega$-incorporation also occured. Polymer microspheres with sizes of 5 to $200 \mu \mathrm{m}$ were obtained. The poly(1-olefins) formed have high molecular weights of $M_{n}>10^{5} \mathrm{~g} \mathrm{~mol}^{-1}$. Adhesives prepared from the microspheres were studied. ${ }^{83}$

As outlined, due to the propensity of the aforementioned $\mathrm{Ni}$ (II) catalysts for chain walking, polymerization of 1-olefins does not occur in a strictly regio- or stereoregular fashion. Dispersions of syndiotactic poly(1-butene) as an example of a stereoregular poly(1-olefin) were prepared via a two-step route, by post-polymerization catalytic hydrogenation ${ }^{84}$ of dispersions of syndiotactic 1,2-polybutadiene (vide infra). ${ }^{85}$ Typical conditions are $125{ }^{\circ} \mathrm{C}$ and 75 bar hydrogen, with a ruthenium catalyst. The dispersed particles (ca. $200 \mathrm{~nm}$ average size) preserve their identity during hydrogenation in the particles, that is they can be regarded as "nanoreactors'. Hydrogenation is virtually complete (> 99.5\% conversion of double bonds). While the starting 1,2-polybutadiene is highly crystalline (vide infra; $\mathrm{T}_{\mathrm{m}} 190{ }^{\circ} \mathrm{C}$ ), hydrogenation under mild conditions (5 bar; $65 \%$ conversion of double bonds) already substantially decreases crystallinity and melting point, and the fully saturated syndiotactic poly(1-butene) was noncrystalline.

As a sidenote, the interest in aqueous dispersions of catalytically prepared polyolefins has also resulted in studies of secondary dispersions. Polyolefin melts, or solutions of polyolefins in hydrocarbon solvents were dispersed in aqueous surfactant solutions. Due to the high viscosity, the former approach is restricted to lower molecular weight materials. ${ }^{86}$ The second approach has also been demonstrated for higher molecular weight (low-crystallinity) polymers, but requires large amounts of solvents which must be removed after the dispersing step, also taking care that coagulation does not occur during this process. ${ }^{87}$ For example, dispersions of semicrystalline polyethylene waxes, ${ }^{86}$ of low-molecular-weight amorphous ethylenepropylene or ethylene-propylene-diene (EPDM) random copolymers, ${ }^{88}$ and of low crystallinity higher molecular weight ethylene-octene copolymers ${ }^{87}$ have been reported.

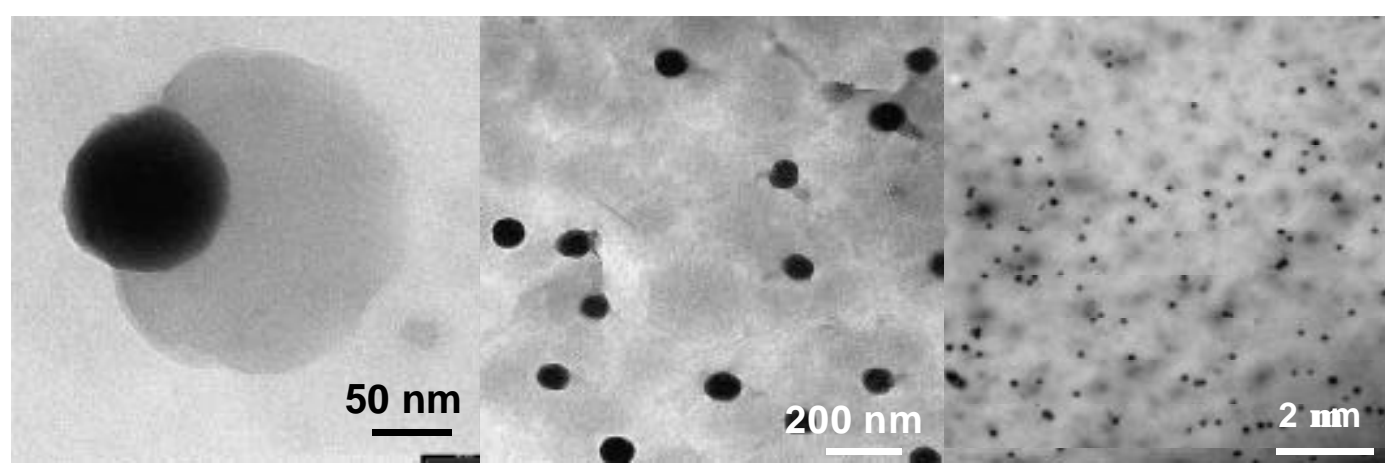

Figure 6. TEM micrographs of silica/polyethylene nanocomposites. Left and middle: nanocomposites particles of silica particles with semicrystalline, linear polyethylene. Right: continuous film with homogeneously dispersed silica particles from nanocomposite dispersions of amorphous, highly branched polyethylene. Reproduced with permission from [89]. Copyright 2006 American Chemical Society.

Nanocomposites of different polymer phases, and of polymers with inorganic nanoparticles have been studied. Catalytic emulsion polymerization of ethylene with nickel catalysts in the presence of lipophilically modified silica nanoparticles (average particle size 70 or $125 \mathrm{~nm}$ ) affords stable dispersions of silica/polyethylene nanocomposite particles (Figure 6). Different morphologies of composites particles were observed depending on the microstructure and 
crystallinity of the polyethylene part, which was controlled by different precatalysts. Composite structures consisting of silica spheres embedded at the periphery of lentil-like crystalline polyethylene particles were formed. At a low-crystallinity of the polyethylene part, individual polyethylene particles are not observed by TEM, but silica particles homogeneously embedded in an amorphous polyethylene matrix (Figure 6). ${ }^{89}$ Free radical polymerization of styrene or butyl acrylate in aqueous dispersions of particles of linear polyethylene, prepared seperately, was found to afford composite particles or separate particles depending on the monomer and reaction conditions. Films formed from these dispersions exhibit homogeneously dispersed polyethylene particles. ${ }^{90}$ Radical polymerization of methyl methacrylate in the presence of the aforementiond secondary dispersions of EPDM as a a seed was studied. For cross-linked EPDM particles, core-shell structures were obtained. Toughening of a PMMA matrix by these particles was demonstrated. ${ }^{91}$

\section{Polybutadiene dispersions}

The free radical polymerization of butadiene and the copolymerization with styrene to styrene-butadiene-rubber (SBR) in emulsion are well known processes performed on a large scale. Polymers with only a limited range of properties in terms of microstructure and thermal behavior are accessible. The typical microstructure of a butadiene homopolymer is $60-80 \%$ 1,4-trans repeat units, 5-20\% 1,4-cis, and 15-20\% 1,2-units. The amorphous polymer has a $\mathrm{T}_{\mathrm{g}}$ of ca. $-80^{\circ} \mathrm{C}$. Via catalytic polymerization, the modes of incorporation (1,2, and 1,4-cis and -trans) and thus the crystallinity and thermal properties can be varied over a wider range. Goodyear $^{92}$ and Japan Synthetic Rubber (JSR) ${ }^{93,94}$ reported the synthesis of syndiotactic 1,2polybutadiene $\left(\mathrm{T}_{\mathrm{m}} 190{ }^{\circ} \mathrm{C}\right)$ by cobalt-catalyzed suspension or emulsion polymerization of butadiene in water. The catalyst system, based on an 'in situ' prepared cobalt catalyst modified with $\mathrm{CS}_{2}$ as a ligand, was previously developed for the 1,2-polymerization of butadiene in solution. ${ }^{95}$ By addition of 'modifiers' the melting point of the polymer can be reduced ${ }^{96} \mathrm{In}$ these reports little consideration was given to the colloidal state of the final reaction mixture, as the studies appeared to aim at isolation of the bulk polymer.

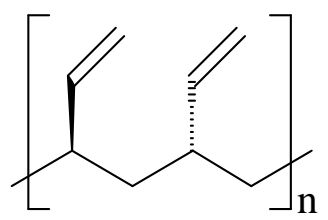

\section{syndiotactic 1,2-polybutadiene}

This aspect, and detailed analyses of the polymer microstructures were reported recently. ${ }^{97}$ The precatalyst was prepared by redution of cobalt(II)octanoate with sodium borohydride in the presence of butadiene in a small amount of toluene. This solution was miniemulsified, and added to a macroemulsion of butadiene in water which also contained a small amount of carbon disulfide. The latter activates the catalyst and starts polymerization. Dispersions of $8 \%$ solids content were obtained without optimization, with average particle sizes of ca. $200 \mathrm{~nm}$. The polymer is 1,2-syndiotactic, with no stereoerrors within the limit of detection by ${ }^{13} \mathrm{C}$ NMR. Only regioerrors in the form of $3 \%$ 1,4-incorporated units are found. Melting points are high $\left(\mathrm{T}_{\mathrm{m}} 190{ }^{\circ} \mathrm{C}\right)$ and the material is crystalline $\left(\Delta \mathrm{H}_{\mathrm{c}} 60 \mathrm{~J} \mathrm{~g}^{-1}\right)$, correspondingly latex particles are hard (Figure 7, left). By modification of the precatalyst with compounds with an electrophilic carbon atom, such as N,N-diphenylformamide, the 1,2-content can be reduced to around $80 \%$. The 1,4-units are still statistically distributed, and largely present as isolated units. The reduction in average 1,2-block length to 7 vs. 25 in the aforementioned crystalline 
polymer results in a strong decrease in crystallinity $\left(\Delta \mathrm{H}_{\mathrm{c}}<10 \mathrm{~J} \mathrm{~g}^{-1}\right)$ and melting point $\left(\mathrm{T}_{\mathrm{m}} 60\right.$ $\left.100{ }^{\circ} \mathrm{C}\right)$. Softer particles are observed by TEM (Figure 7 , right).

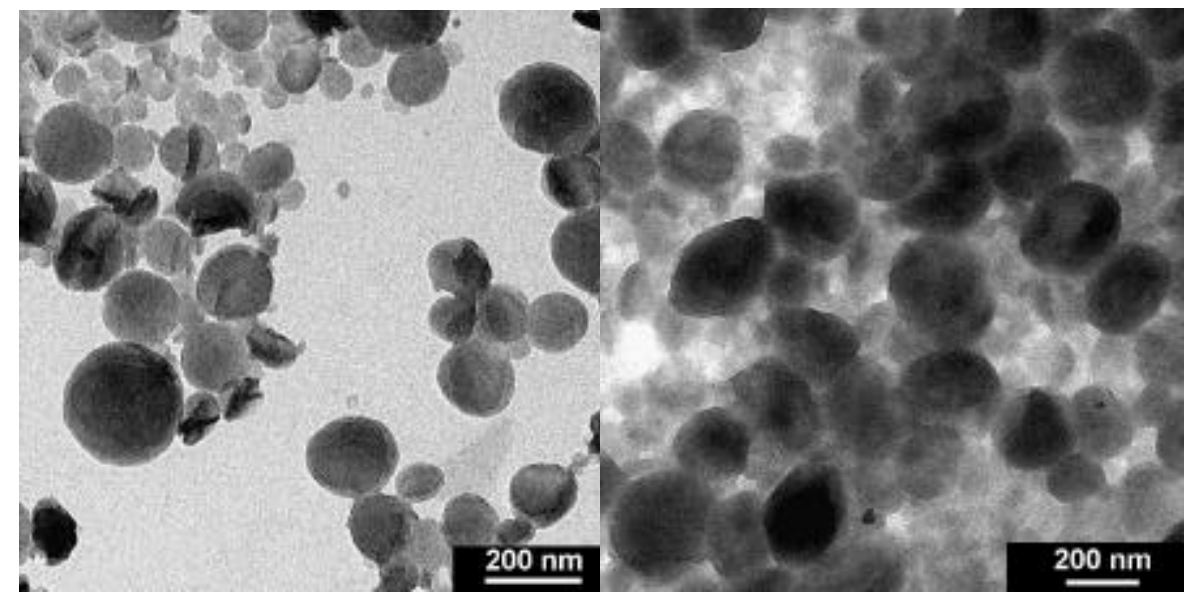

Figure 7. TEM micrographs of syndiotactic 1,2-polybutadiene latex particles. Left: crystalline particles, $97 \%$ 1,2-units. Right : low crystalline particles, $85 \%$ 1,2-units. Reproduced with permission from [97]. Copyright 2005 American Chemical Society.

Studies of the particle number over time are complicated by the reaction being relatively rapid, and the large impact of errors in the particle sizes on the particle numbers calculated (V $\sim \mathrm{r}^{3}$ ). Nonetheless, studies of the formation of dispersions of the lower crystalline polymer indicate that no substantial numbers of new particles are formed during the polymerization. A possible mechanism is that the monomer diffuses to the miniemulsion droplets containing the catalyst, where it is polymerized. As the polymer is low crystalline and swellable with monomer and toluene, it does not precipitate to form new particles, but rather a miniemulsion droplet affords one particle.

Very small particles of syndiotactic 1,2-polybutadiene can be prepared from microemulsions. Butadiene, containing the above lipophilic cobalt catalyst, was microemulsified. Polymerization was started by addition of $\mathrm{CS}_{2}$ to the microemulsion. E.g. a dispersion with 6 wt.-\% solids content of high molecular weight polymer $\left(M_{w} 2 \times 10^{5} \mathrm{~g} \mathrm{~mol}^{-1} ; \mathrm{M}_{\mathrm{w}} / \mathrm{M}_{\mathrm{n}} 2.3\right)$ with $14 \mathrm{~nm}$ volume average particle size resulted. ${ }^{77}$

\section{Polyalkenamer dispersions}

Ring opening metathesis polymerization (ROMP) of cyclic olefins affords polyalkenamers. Simple metal salts like $\mathrm{RuCl}_{3}$ can be used as a precatalyst, but ROMP in general has profited strongly from defined metal alkylidenes as precursors. ${ }^{98}$ These are also available commercially. Strained cyclic olefins like norbornene are particularly reactive, unstrained cyclic olefins like cyclooctene require a more careful choice of catalyst. By comparison to other catalytic polymerization methods, ROMP (with appropriate catalysts) is particularly suited for substrates containing functional groups, and it can be carried out in a living fashion. ${ }^{28,29,99}$<smiles>C=CC1CCC(C=C)C1</smiles>

poly(norbornene) from ROMP

ROMP of 2,3-bis(methoxymethyl)-7-oxa-norborn-5-ene by $\mathrm{RuCl}_{3}$ in the presence of a poly(ethylene oxide- $b$-propylene oxide- $b$-ethylene oxide) triblock copolymer (Synperonic 
F127) afforded stable dispersions of higher molecular weight polymer $\left(10^{5} \mathrm{~g} \mathrm{~mol}^{-1}\right.$ vs. PS standards). ${ }^{100}$ The monomer and the precatalyst are water soluble whereas the polymer is insoluble, in this sense the reaction is akin to a dispersion polymerization. Particle sizes are 40 to $300 \mathrm{~nm}$. With a monomer / $\mathrm{Ru}$ ratio of only 90 , the demonstrated catalyst efficiency is quite low (complete conversion is observed, such that this corresponds to a productivity of 90 turnovers).

ROMP of norbornene in emulsion was studied in detail with various ruthenium alkylidenes as precatalysts. ${ }^{101}$ Norbornene (macro-)emulsions were polymerized by water-soluble ruthenium alkylidenes to afford stable dispersions. An isolated ruthenium alkylidene complex, or an alkylidene prepared in situ from ethyl diazoacetate were studied. Catalyst productivities of several $10^{3}$ TO were observed. Latices with solids contents of up to $46 \%$ were obtained, which were electrostatically stabilized by the anionic surfactants SDS or Dowfax3B2. Monomer conversion is typically $80 \%$. The average particle sizes were only 50 to $80 \mathrm{~nm}$. Unlike typical free radical emulsion polymerizations, the particle number increases continuously with conversion, indicating continuous nucleation. The observed dependence of particle numbers on reaction conditions indicates homogeneous nucleation to occur, even in the presence of surfactant micelles. The ratio of particles to $\mathrm{Ru}$ is $10^{-2}$ to $10^{-3}$. From electon microsocopy of the polymer particles, the authors putatively suggest the final particles to be formed by coagulation of primary particles, which are formed by a single active site via homogeneous nucleation. The ROMP of unstrained cyclic olefins was studied with the commercially available precatalyst $\left[\left(\mathrm{PCy}_{3}\right)_{2} \mathrm{Cl}_{2} \mathrm{Ru}=\mathrm{CHPh}\right]$. A miniemulsion of a solution of this lipophilic compound in a small amount of toluene was mixed with cyclooctene or 1,5-cyclooctadiene monomer. Dispersions of high molecular weight polymers $\left(M_{n}\right.$ ca. $\left.10^{5} \mathrm{~g} \mathrm{~mol}^{-1}, M_{w} / M_{n} 1.6\right)$ resulted, which are however prone to flocculation.

ROMP of norbornene miniemulsions was studied. With a water soluble precatalyst $\left(\mathrm{RuCl}_{3}\right)$, stable dispersions were obtained with average particles sizes of 200 to $500 \mathrm{~nm}$ (polymer $\mathrm{M}_{\mathrm{n}}$ $1.5 \times 10^{4} \mathrm{~g} \mathrm{~mol}^{-1}, \mathrm{M}_{\mathrm{w}} / \mathrm{M}_{\mathrm{n}}$ 1.6). When a steric stabilizer was utilized, namely a poly(styrene- $b$ ethylene oxide), the particle sizes were about the same size as the miniemulsion droplets. ${ }^{102}$

With microemulsions, again very small particles are accessible. Commercially available ruthenium alkylidenes $\left[\left(\mathrm{PCy}_{3}\right)_{2} \mathrm{Cl}_{2} \mathrm{Ru}=\mathrm{CHPh}\right]$ or $\left[\left(\mathrm{PCy}_{3}\right)\left(\eta-C-\mathrm{C}_{3} \mathrm{H}_{4} \mathrm{~N}_{2} \mathrm{Mes}_{2}\right) \mathrm{Cl}_{2} \mathrm{Ru}=\mathrm{CHPh}\right]$ were employed for the polymerization of norbornene or cyclooctene and cyclooctadiene, respectively. Due to the high reactivity of the catalyst precursors, they had to be dispersed seperately from the monomer. Mixing of a microemulsion of the catalyst precursor in toluene with a monomer microemulsion proved viable for the synthesis of stable dispersions. Average particle sizes of 23 to $32 \mathrm{~nm}$ were observed by DLS. ${ }^{77}$

\title{
Polynorbornene dispersions
}

Norbornene can also be polymerized by an insertion type mechanism. A characteristic of the polynorbornenes formed is an amorphous nature and a high $\mathrm{T}_{\mathrm{g}}$ of $>300{ }^{\circ} \mathrm{C} .{ }^{103}$

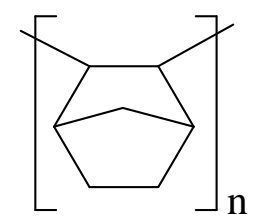

\author{
poly(norbornene) \\ from insertion polymerization
}

An early example of an insertion-type polymerization of norbornene affording an aqueous latex was reported in 1993. ${ }^{104-106}$ Norbornene was reacted in aqueous emulsion with SDS as 
an emulsifier and $\mathrm{PdCl}_{2}$ as a precatalyst, to afford dispersions with particle sizes of only 10 to $20 \mathrm{~nm}$. The material obtained are low molecular weight oligomers with a degree of polymerization of only $\mathrm{DP}_{\mathrm{n}} \sim 10 . \mathrm{PdCl}_{2}$ is slightly water-soluble, and the authors have reasoned that polymerization occurs preferentially at the interface between water and monomer droplets. However, no experimental evidence or even suggestions for the nature of the polymerization active species were provided.

The polymerization of norbornene miniemulsions was studied in detail. ${ }^{107}$ With water-soluble or water-insoluble catalysts polymerization to dispersions occurs. In the latter case, a lithium tetraarylborate was used as the activator. Its function is to abstract chloride from the precatalyst $\left[\left(\eta^{3}\right.\right.$-allyl $\left.) \mathrm{Pd}\left(\mathrm{PCy}_{3}\right) \mathrm{Cl}\right]$ to form a polymerization active cationic species. Hereby, the water-insoluble precatalyst can be miniemulsified together with the monomer. Polymerization is triggered by addition of the water-soluble activator. At the monomer to metal complex molar ratio of $10^{3}$ studied, conversion is complete. Broad particle size distributions are obtained as evident from TEM. Number average particle sizes are 40 to $80 \mathrm{~nm}$ as determined by light scattering. The authors find that at low surfactant concentrations there is some similarity between the distributions of droplets and particles, although it can not be concluded that the reaction occurs under ideal miniemulsion conditions, that is all initial droplets are converted to a particle. Curiously, no $\mathrm{T}_{\mathrm{g}}$ was observed. Due to the insolubility of the material prepared, it remains open whether it is higher molecular weight polymer, the presence of low molecular weight oligomers can not be excluded. To this end, it can be noted that in similar suspension-type polymerizations with the same catalyst and 5-butylnorbornene as a monomer, high molecular weight polymer with $\mathrm{M}_{\mathrm{n}} 4 \times 10^{5} \mathrm{~g} \mathrm{~mol}^{-1}\left(\mathrm{M}_{\mathrm{w}} / \mathrm{M}_{\mathrm{n}} 2.7\right)$ was observed. ${ }^{108}$ In an independant preliminary report homopolymerization of norbornene, starting from monomer miniemulsions or macroemulsions, was also reported to afford dispersions of 50 to $800 \mathrm{~nm}$ average particle size with solids contents of $3 \%$, without further specification of the catalyst used. $^{109}$

Very recently, dispersions of norbornene-rich norbornene-ethylene copolymers were reported. ${ }^{110}$ A palladium catalyst, formed in situ from $\left[\mathrm{Pd}^{0}(\mathrm{dba})_{2}\right]$ and an ortho-sulfonated triarylphosphine, was utilized (the function of the sulfonate group is not water-solubility, but coordination to the metal in this case ${ }^{111}$ ). The water-insoluble catalyst was dispersed as a miniemulsion of a solution in methylene chloride, and norbornene was added and the mixture exposed to ethylene pressure. Dispersions of particles with average sizes of 200 to $800 \mathrm{~nm}$, with solids contents up to $9 \%$ resulted. Heterogeneous polymers are formed which consist of an ethylene-rich and a norbornene-rich fraction. The latter possesses a high $\mathrm{T}_{\mathrm{g}}$ of up to 170 ${ }^{\circ} \mathrm{C}$.

\section{Polyketone dispersions}

Polyketones are obtained by catalytic copolymerization of olefins with CO. Due to the polymerization mechanism, the polyketones have a strictly alternating structure. ${ }^{112-114}$ Carbon monoxide is an attractive starting material due to its low cost, and accessability from nearly any carbon-containing raw material. Polyketones are unique in being a polymer prepared by catalytic polymerization which contains a very large number of oxygen containing functional groups. By comparison to most other polymers prepared as dispersions by catalytic polymerization, polyketones are more polar. Polyketones are, for example, resistant to hydrocarbon solvents. As a drawback, the large number of carbonyl groups renders polyketones sensitive to photochemical degradation. Also, condensation cross-linking can occur, particularly at 
higher temperatures required for thermoplastic processing (an issue not applicable to traditional applications of polymer dispersions). Ethylene/propylene/CO alternating copolymers have been developed as engineering thermoplastics, however this product was abandoned. ${ }^{115}$<smiles>[R]C(CC(C)(C)C)CC(C)(C)C</smiles>

alternating carbon monoxide / 1-olefin copolymer

For the preparation of polyketone dispersions, lipophilic palladium catalysts modified with diphosphine ligands were employed via miniemulsion techniques, or water soluble catalysts were employed. ${ }^{116-118}$ In view of classical film formation, 1-olefin/CO co- or terpolymers are attractive due to their relatively low crystallinity, by comparison to highly crystalline ethylene/CO copolymers (which melt at $>250{ }^{\circ} \mathrm{C}$ ). Dispersions of alternating copolymers of $\mathrm{CO}$ with various 1-olefins, ranging from propylene to 1-octadecene, and of terpolymers with undec-10-enoic acid and ethylene or 1-olefins have been reported (Figure 8). Incorporation of undecenoic acid increases colloidal stability of the dispersions formed. Likely, this amphiphilic comonomer will be arranged preferentially at the particle surface during polymerization, and in the final particles the hydrophilic carboxylic acid groups covalently attached to the polymer will contribute to colloidal stability of the particles. This corresponds to the concept of polymerizable surfactants ('surfmers'), well known in free-radical polymerization. ${ }^{119}$

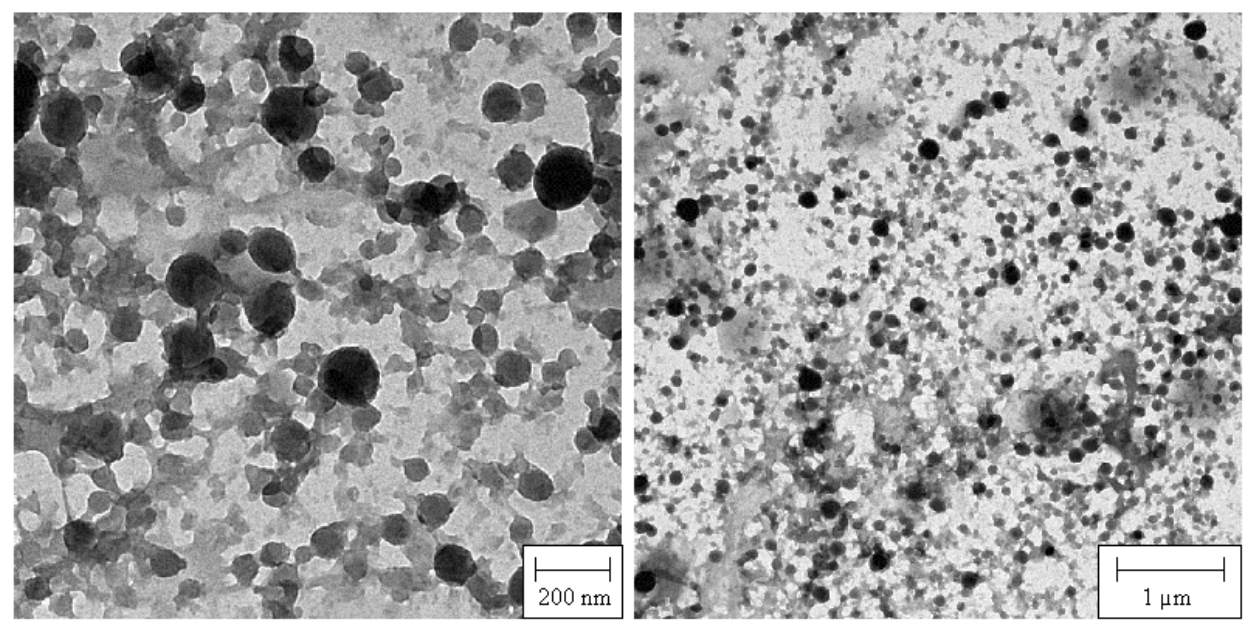

Figure 8. TEM images of an ethylene-undecenoic acid-carbon monoxide terpolymer latex. Reproduced with permission from [116]. Copyright 2002 American Chemical Society.

Typical polymerization conditions are temperatures of $70{ }^{\circ} \mathrm{C}$ and a carbon monoxide pressure of 30 to $60 \mathrm{~atm}$. Polymer molecular weights are in the range $\mathrm{M}_{\mathrm{n}} 10^{4}$ to $10^{5} \mathrm{~g} \mathrm{~mol}^{-1}\left(\mathrm{M}_{\mathrm{w}} / \mathrm{M}_{\mathrm{n}} 2\right.$ to 4). Average particle sizes are in the range of 30 to $500 \mathrm{~nm}$. Solids contents of $25 \%$ were reported. The polymers are low crystalline or amorphous, with $\mathrm{T}_{\mathrm{g}}$ ranging from $-55^{\circ} \mathrm{C}$ to +10 ${ }^{\circ} \mathrm{C}$ (cf. Figure 8). Reported productivities are ca. $1.5 \times 10^{4} \mathrm{TO}$. The catalysts are stable for hours under aqueous conditions.

\section{Dispersions of conjugated polymers}

Conjugated, conductive or semiconductive polymers are of technical interest for flexible displays, low-cost and large scale displays in general, thin film transistors, or antistatic coatings, to name only a few examples. ${ }^{120}$ However, ever since the seminal discovery of Heeger, McDiarmid and Shirakawa of the conductive nature of ('doped') polyacetylene, ${ }^{124}$ the 
processing of conductive polymers has been a critical issue. ${ }^{121}$ The rigid conjugated polymer backbone generally results in very low solubilities in organic solvents and in thermal properties that prohibit thermoplastic processing. This can be overcome by introducing substituents as side chains, which however also alters the electronic properties (which may be desirable or undesirable) and often requires additional synthetic effort. Dispersions of conjugated polymers are therefore an attractive topic to study. Printing techniques, which allow for rapid processing with spatial resolution, are developed for aqueous systems. The preparation of secondary dispersions of conjugated polymers has been investigated, however this again requires fusability of the polymers, or solubility in an organic solvent. ${ }^{122,123}$

Polyacetylene is the structurally simplest conjugated polymer, and also historically it is the prototype of this class of polymers. ${ }^{124-131}$ Neat unsubstituted polyacetylene was considered unprocessable until recently. For example, to obtain a neat polyacetylene film the polymer had to be prepared directly in this shape by polymerization on a liquid surface, ${ }^{126,127}$ or on a solid substrate. ${ }^{132}$ With palladium catalysts modified with bulky phosphine ligands, acetylene can be polymerized in aqueous emulsion to afford stable dipersions. ${ }^{133,134}$ The catalyst was stable for hours in the acetylene polymerization in emulsion; an overall productivity of $1.4 \times$ $10^{3}$ TO was observed (in the polymerization of phenylacetylene to stable emulsions, productivities were > $\left.10^{5} \mathrm{TO}\right) .{ }^{133,134}$ The lipophilic catalyst was employed as a miniemulsion or microemulsion in a small amount of solvent (hexane). With both methods, very small polyacetylene particles of ca. $20 \mathrm{~nm}$ size result (Figure 9). A possible, albeit speculative, particle formation mechanism is that polymerization starts in the hexane mini- or microemulsion droplets. As polyacetylene is highly insoluble, it should precipitate rapidly during polymerization to form particles, which may exit the droplets, stabilizing themselves by adsorption of surfactant. In case the active sites remain in the hexane droplets, particles could be formed continuously.

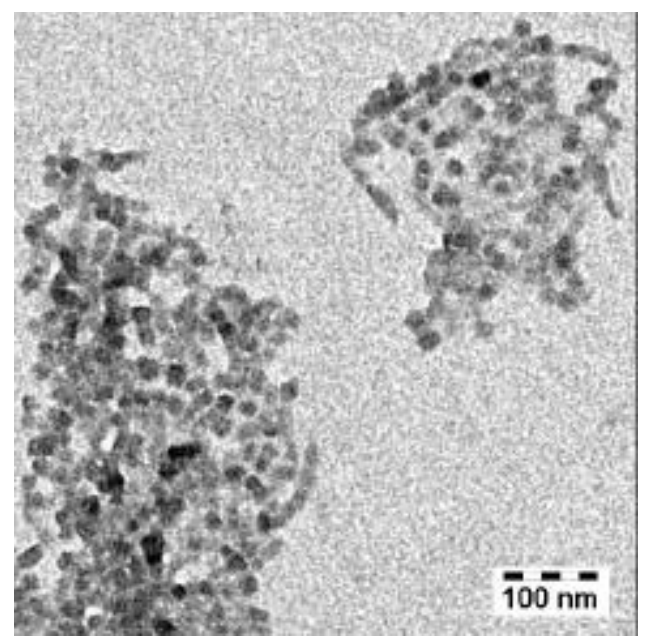

Figure 9. TEM micrograph of polyacetylene particles. Reproduced with permission from $[133,134]$. Copyright 2006 Wiley-VCH.

Polyacetylene dispersions with polymer solids contents of $7 \%$ were reported. Continuous films with a metallic luster could be obtained on various substrates, such as glas or paper, by simple dip-coating or spreading of dispersions on the substrate and subsequent drying. Films doped with iodine had a conductivity of ca. $50 \mathrm{~S} \mathrm{~cm}^{-1}$. Reported conductivities of bulk polyacetylene vary considerably, and are influenced by orientation induced by stretching, and the doping procedure. Values range from $10^{2}$ to $10^{5} \mathrm{~S} \mathrm{~cm}^{-1}{ }^{125,130,131,135}$ It is to be expected that the 
surfactant shell of particles and voids in the film decrease conductivity signficantly. The conductivity found for the films shows that this, however, does not detoriate conduction. The dispersions were ink-jet printed onto paper, to generate a functioning circuit (Figure 10). The thickness of the printed films was ca. $100 \mathrm{~nm}$. After doping, the resistance between the two poles ( $\mathrm{C} 1$ and $\mathrm{C} 2$ ) was $10^{5}$ to $10^{6} \Omega$, depending on which key is contacted by touching (the resistance can be translated to a tone of variable frequency). The resistance can be converted to a tone by an appropriate sound generator, allowing for the playing of simple tunes.

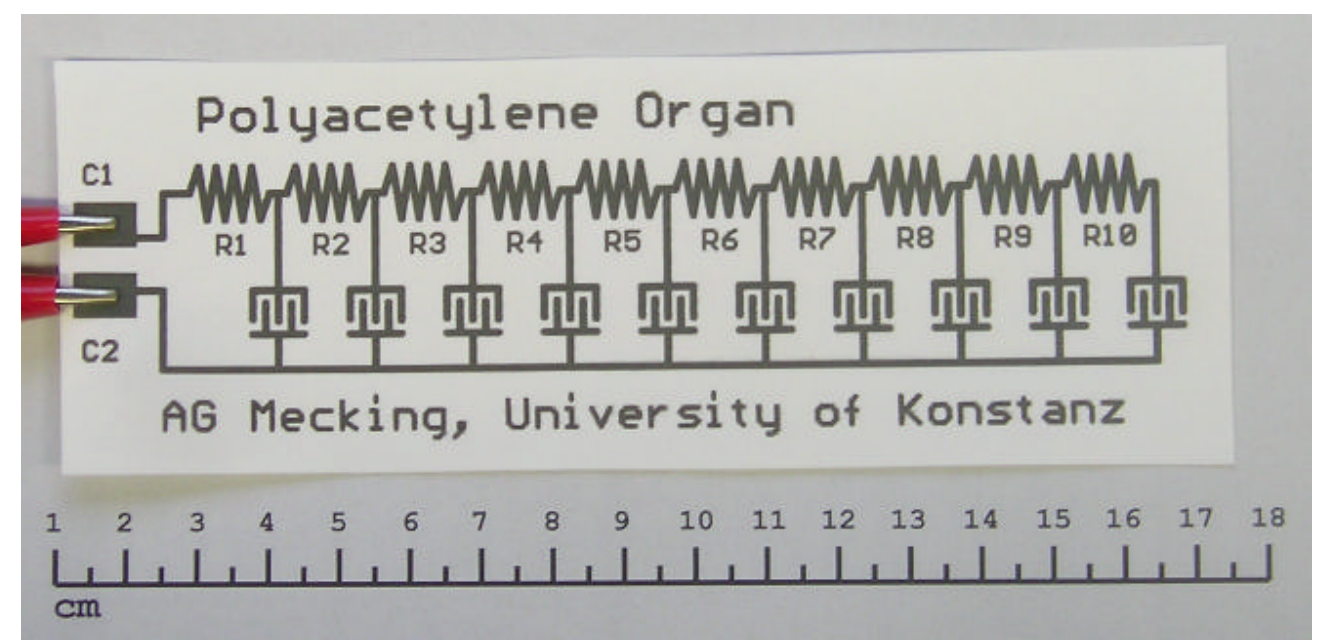

Figure 10. Ink-jet printed polyacetylene functional circuit board. Reproduced with permission from [133,134]. Copyright 2006 Wiley-VCH.

\section{Summary and Conclusions}

While scattered reports on the synthesis of polymer dispersions by catalytic polymerization can be found from the 1990s, the topic has been studied systematically only since the late 1990s by a number of academic and industrial research groups. Starting in the year 2000, this has resulted in an increasing number of publications. Catalytic polymerization in aqueous emulsion has been demonstrated to be a general method for the synthesis of polymer dispersions. Various types of catalytic polymerizations based on different chain growth mechanisms, namely insertion polymerization, diene polymerization and ring opening metathesis polymerization have been investigated. Polyolefin-, polyketone-, polynorbornene-, polyalkyne-, 1,2-polybutadiene-, and polyalkenamer-dispersions have been studied. For a given polymer type, microstructures and thus crystallinities can be adjusted by various methods. Via the catalyst, branching, tacticity or regioregularity can be controlled. An alternative is copolymerization of small amounts of appropriate monomers. As a rather particular case, crystallinity can be adjusted by catalytic post-polymerization hydrogenation in the latex particles. A wide range of crystallinities, from highly crystalline to amorphous, and of glass transition temperatures, ranging from $\mathrm{T}_{\mathrm{g}}<-80{ }^{\circ} \mathrm{C}$ to $170{ }^{\circ} \mathrm{C}$, is accessible. Substantial solids contents in the two-digit range have been reported in various cases, demonstrating that the dispersions prepared are not purely academic in this respect. The polymer particles can possess unique morphologies. This is exemplified by the structures of polyethylene particles, which at small particle sizes consist of a single lamella.

In terms of the monomers employed catalytic synthesis of polymer dispersions is largely complementary to free radical emulsion polymerization. By contrast to styrene, acrylates and 
acrylic acid, and vinyl acetate as the major components of todays emulsion polymerisates, the $\mathrm{C}_{2}$ to $\mathrm{C}_{4}$ monomers susceptible to catalytic polymerization are obtained directly from steam cracking without further energy and raw materials consuming conversions. This makes them attractive from an economical and ecological point of view.

Mostly hydrocarbon polymers have been studied, though oxygen-containing polymers are also accessible, as illustrated most clearly by polyketones. Commercial dispersions made by free radical emulsion polymerization often contain acrylic acid-copolymers which enhance interaction with polar substrates like paper, metals or inorganic oxides. This is a difference to the aforementioned hydrocarbon polymers. The possibility of incorporation of (co)monomers with oxygen-containing polar groups, like undec-10-en-1-ol in polyethylene dispersions, has been demonstrated. Incorporation of acrylates or vinyl acetate during the catalytic polymerization in emulsion with notable catalyst activities is an attractive but formidable task.

Though very high catalyst activities and productivities have been demonstrated in some cases, catalyst activtiy is a major issue. Catalysts with high intrinsic chain growth rates are desirable. Moreover, catalyst deactivation by water in a reversible or irreversible fashion must be considered. Some of the catalysts used for the preparation of the different dispersions discussed have been shown to be susceptible to such deactivation, in other cases this appears likely. The extent of deactivation will depend subtly on the colloidal state of the reaction mixture at the different stages of polymerization. Finally, a more comprehensive picture of polymerization kinetics, particle formation and growth, and the location of the active sites for a given polymerization reaction and catalyst is required to increase activities.

Albeit catalyst synthesis and design is a major topic in the context of catalytic synthesis of polymer dispersions, in many cases catalysts based on commercially available compounds have been employed. Studies of catalytic polymerization in aqueous systems therefore are not restricted to laboratories focussed on organometallic chemistry.

First insights have been gained into particle formation mechanisms. In some cases parallels can be drawn to free radical polymerization, such as polymerization in monomer miniemulsion droplets. However, studies with water-soluble catalysts indicate that rather unique particle formation mechanisms can be operative. This is also reflected in the accessibility of particles with extremely small sizes. The kinetics will obviously be entirely different from free radical polymerization due to the different mechanisms of chain initiation, growth, and termination or transfer, and they will also differ from catalytic polymerization in non-aqueous polymerizations e.g. due to different local monomer concentrations.

Beyond the traditional established applications of polymer dispersions, the dispersions from catalytic polymerization can be of interest for crystalline thin films, porous materials, scratch resistant coatings or processing of conjugated polymers to name a few examples. More fundamental aspects of current and future interest are the structures of dispersed particles and dispersions, and structure formation from these unique dispersions.

\section{Acknowledgement}

Financial support of our studies on catalytic polymerization in aqueous systems by BASF AG, DFG (Me1388/3 and IGK667), BMBF (03X5505) and the Alexander von HumboldtFoundation is gratefully acknowledged. The author is indebted to the Fonds der Chemischen Industrie and to the Hermann-Schnell-Foundation. I would like to thank the members of the BASF polymer research laboratory for many stimulating discussions. 


\section{References}

1) Lovell PA, El-Aasser MS (eds) (1997) Emulsion Polymerization and Emulsion Polymers. Wiley, Chichester.

2) Distler D (ed) (1999) Wäßrige Polymerdispersionen. VCH, Weinheim.

3) Urban D, Takamura K (2002) Polymer Dispersions and Their Industrial Applications. Wiley-VCH, Weinheim.

4) Lagaly G, Schulz O, Zimehl R (1997). Dispersionen und Emulsionen. Steinkopff, Darmstadt.

5) Fitch RM (1997). Polymer Colloids: a Comprehensive Introduction. Academic Press, San Diego.

6) Herk AM (ed) (2005) Chemistry and Technology of Emulsion Polymerisation. Blackwell, Oxford.

7) Caruso F (ed) (2003). Colloids and Colloid Assemblies. Wiley-VCH, Weinheim.

8) Antonietti M, Tauer K (2003) Macromol. Chem. Phys. 204: 207-219.

9) Lowe AB, McCormick CL (2002) Aust. J. Chem. 55: 367-379.

10) Prescott SW, Ballard MJ, Rizzardo E, Gilbert RG (2002) Aust. J. Chem. 55: 415-424.

11) Cunningham MF (2002) Progr. Polym. Sci. 27: 1039-1067.

12) Monteiro MJ, Charleux B (2005). In Herk AM (ed) Chemistry and Technology of Emulsion Polymerisation. Blackwell, Oxford, pp. 111-139.

13) Qiu J, Charleux B, Matyjaszewski K (2001) Progr. Polym. Sci. 26: 2083-2134.

14) Mecking S, Claverie J (2003). In Rieger B, Baugh LS, Kacker S, Striegler S (eds.) Late Transition Metal Polymerization Catalysis. Wiley-VCH, Weinheim, pp. 231-278.

15) Weyenberg DR, Findlay DE, Cekada J, Bey AE (1969) J. Polym. Sci. C 27: 27-34.

16) Maitre C, Ganachaud F, Ferreira O, Lutz JF, Paintoux Y, Hemery P (2000) Macromolecules 33 : 7730-36.

17) Landfester K, Tiarks F, Hentze HP, Antonietti M (2000) Macromol. Chem. Phys. 201: 1-5.

18) Dieterich D, Uhlig K (2003) in Ullmann's Encylopedia of Industrial Chemistry, $6^{\text {th }}$ edn. Wiley-VCH, Weinheim. Volume 28: pp 667-722.

19) Coates GW, Hustad PD, Reinartz S (2002) Angew. Chem. 114: 2340-2361.

20) Coates GW, Hustad PD, Reinartz S (2002) Angew. Chem. Int. Ed. 41: 2236-2257

21) Makio H, Kashiwa N, Fujita T (2002) Adv. Synth. Catal. 344: 477-493.

22) Mülhaupt R (2003) Makromol. Chem. Phys. 204: 289-327.

23) Manders B, Sciandrone L, Hauck G, Kristen MO (2001) Angew. Chem. 113: 4139-4141.

24) Manders B, Sciandrone L, Hauck G, Kristen MO (2001) Angew. Chem. Int. Ed. 40: 4006-4007.

25) Ittel SD, Johnson LK, Brookhart M. (2000) Chem. Rev. 100: 1169-1203.

26) Mecking S (2001) Angew. Chem. 113, 550-557.

27) Mecking S (2001) Angew. Chem Int. Ed.. 40: 534-540.

28) Mecking S, Held A, Bauers FM (2002) Angew. Chem. 114: 564-582.

29) Mecking S, Held A, Bauers FM (2002) Angew. Chem Int. Ed. 41: 544-561.

30) Claverie JP, Soula R (2003) Prog. Polym. Sci. 28: 619-662.

31) Verspui G, Papadogianakis G, Sheldon RA (1998) Chem. Commun. 401-402.

32) Bianchini C, Man Lee H, Meli A, Moneti S, Patinec V, Petrucci G, Vizza F (1999) Macromolecules 32: 3859-3866.

33) Lynn DM, Mohr B, Grubbs RH (1998) J. Am. Chem. Soc. 120: 1627-1628.

34) Hristov IH, DeKock RL, Anderson GDW, Göttker genannt Schnetmann I, Mecking S, Ziegler T (2005) Inorg. Chem. 44: 7806-7818.

35) Berkefeld A, Mecking S (2006) Angew. Chem. 118: 6190-6193.

36) Berkefeld A, Mecking S (2006) Angew. Chem. Int. Ed. 45: 6044-6046.

37) Mecking S (2004) in Herrmann WA, Cornils B (eds.) Aqueous Phase Organometallic Catalysis. Wiley-VCH, 2nd edition, Weinheim, pp. 576-592.

38) Landfester K (2001) Macromol. Rapid Commun. 22: 896-936.

39) Asua JM (2002) Progr. Polym. Sci. 27: 1283-1346.

40) Schork FJ, Luo Y, Smulders W, Russum JP, Butte A, Fontenot K (2005) Adv. Polym. Sci. 175: 129-255.

41) Mecking S, Monteil V, Huber J, Kolb L, Wehrmann P (2006) Makromol. Symp. 236: 117-123.

42) Held A, Bauers FM, Mecking S (2000) Chem. Commun. 301-302.

43) Tomov A, Broyer JP, Spitz R (2000) Macromol. Symp. 150: 53-58.

44) Bauers FM, Mecking S (2001) Macromolecules 34: 1165-1171.

45) Soula R, Novat C, Tomov A, Spitz R, Claverie J, Drujon X, Malinge J, Saudemont T (2001) Macromolecules 34: 2022-2026.

46) Soula R, Saillard B, Spitz R, Claverie J, Llaurro MF, Monnet C (2002) Macromolecules 35: 1513-1523.

47) Bauers FM, Chowdhry MM, Mecking S (2003) Macromolecules 36: 6711-6715.

48) Bauers FM, Mecking S (2001) Angew. Chem. 113: 3112-3115.

49) Bauers FM, Mecking S (2001) Angew. Chem Int. Ed. 40: 3020-3022. 
50) Zuideveld MA, Wehrmann P, Röhr C, Mecking S (2004) Angew. Chem. 116: 887-891.

51) Zuideveld MA, Wehrmann P, Röhr C, Mecking S (2004) Angew. Chem Int. Ed. 43: 869-873.

52) Keim W, Kowaldt FH, Goddard R, Krueger C (1978) Angew. Chem. 90: 493.

53) Keim W, Kowaldt FH, Goddard R, Krueger C (1978) Angew. Chem. Int. Ed. 17: 466-7.

54) Ostoja-Starzewski KA, Witte J (1985) Angew. Chem. 97: 610-2.

55) Ostoja-Starzewski KA, Witte J (1985) Angew. Chem. Int. Ed. 24: 599-601.

56) Klabunde U, Ittel SD (1987) J. Mol. Cat. 41:123-34.

57) Johnson LK, Bennett AMA, Ittel SD, Wang L, Parthasarathy A, Hauptman E, Simpson RD, Feldman J, Coughlin EB (1998) DuPont: WO98/30609.

58) Younkin TR, Connor EF, Henderson JI, Friedrich SK, Grubbs RH, Bansleben DA (2000) Science 287: 460-2.

59) Moehring VM, Fink G (1985) Angew. Chem. 97: 982-4.

60) Moehring VM, Fink G (1985) Angew. Chem. Int. Ed. Engl. 24, 1001-3

61) Johnson LK, Killian CM, Brookhart M (1995) J. Am. Chem. Soc. 117: 6414-6415.

62) Claverie JP, Kumar A, Skupov KM (2005) Polym. Mat. Sci. Eng. 93: 952-953.

63) Wehrmann P, Zuideveld MA, Thomann R, Mecking S (2006) Macromolecules 39: 5995-6002.

64) Arndt M, Beulich I (1998) Macromol. Chem. Phys. 199: 1221-1232.

65) Bauers FM, Thomann R, Mecking S (2003) J. Am. Chem. Soc. 125: 8838-8840.

66) Clausse D (1998) J. Therm. Anal. 51: 191-201.

67) Montenegro R, Antonie tti M, Mastai Y, Landfester K (2003) J. Phys. Chem. B 107: 5088-5094.

68) Cormia RL, Price FP, Turnbull D (1962) J. Chem. Phys. 37: 1333-1340.

69) Ross GS, Frolen LJ (1975) J. Res. NBS 79A: 701-711.

70) Hoffman JD (1983) Polymer 24: 3-26.

71) Arnal ML, Müller AJ (1999) Macromol. Chem. Phys. 200: 2559-2576.

72) Candeau, F. (1992). In: Paleos CM (ed) Polymerization in Organized Media, Gordon and Breach Sci. Publ., Philadelphia, pp 215-283.

73) Antonietti M, Basten R, Lohmann S (1995) Macromol. Chem. Phys.: 196, 441-466.

74) Pavel FM (2004) J. Disp. Sci. Tech. 25: 1-16.

75) Kolb L, Monteil V, Thomann R, Mecking S (2005) Angew. Chem. 117: 433-436.

76) Kolb L, Monteil V, Thomann R, Mecking S (2005) Angew. Chem. Int. Ed. 44: 429-432.

77) Monteil V, Wehrmann P, Mecking S (2005) J. Am. Chem. Soc. 127: 14568-14569

78) Göttker genannt Schnetmann I, Korthals B, Mecking S (2006) J. Am. Chem. Soc. 128: 7708-7709

79) Barham PJ, Chivers RA, Keller A, Martinez-Salazar J, Organ, SJ (1985) J. Mater. Sci. 20: 1625-1630.

80) Barham PJ, Jarvis DA, Keller, AJ (1982) Polym. Sci. Polym. Phys. Ed. 20: 1733-1748.

81) Strobl G (2000) Eur. Phys. J. E. 3: 165-183.

82) Wehrmann P, Mecking S (2006) Macromolecules 39: 5963-5964.

83) Brown KA, Kesti MR, Stewart E, McGrath J (1997) WO 97/48740. Applicant: 3M.

84) Leube HF, Schmidt-Thümmes J, Zeller E, Maas H (2002) US Pat. 6403727 to BASF.

85) Bastero A, Mecking S (2005) Macromolecules 38: 220-222.

86) Schmidt-Thümmes J, Koehler G (1991) DE 3924396. Applicant: BASF.

87) Walther BW, Bethea JR (1996) U.S. Pat. 5574091 to Dow.

88) Tillier DL, Meuldijk J, Koning CE (2003) Polymer 44: 7883-7890.

89) Monteil V, Stumbaum J, Thomann R, Mecking S (2006) Macromolecules 39: 2056-2062.

90) Kolb L, Thomann R, Mecking S (2004) Macromol. Rapid Commun. 25: 1824-1828.

91) Tillier DL, Meuldijk J, Höhne GWD, Frederik PM, Regev O, Koning CE (2005) Polymer 46: 7094-7108.

92) Henderson JN, Donbar KW, Barbour JB, Bell AJ (1984) US Pat. 4429085 to Goodyear.

93) Ono H, Matsumura Y, Okuya E (1985) Eur. Pat. Appl. 152175. Applicant: Japan Synthetic Rubber.

94) Ono H, Kato T (2000) J. Polym. Sci. Part. A Polym. Chem. 38: 1083-1089.

95) Ashitaka H, Jinda K, Ueno H (1983) J. Polym. Sci. Polym. Chem. 21: 1951-1972.

96) Burroway GL (1994) US Pat. 5278263 to Goodyear.

97) Monteil V, Bastero A, Mecking S (2005) Macromolecules 38: 5393-5399.

98) Trnka TM, Grubbs RH (2001) Acc. Chem. Res. 34 : 18-29.

99) Lynn DM, Kanaoka S, Grubbs RH (1996) J. Am. Chem. Soc. 118: 784-90.

100) Lu SY, Quayle P, Booth C, Yeates SG, Padget JC (1993) Polymer Int. 32:1-4.

101) Claverie JP, Viala S, Maurel V, Novat C (2001) Macromolecules 34: 382-388.

102) Quemener D, Heroguez V, Gnanou Y (2005) Macromolecules 38: 7977-7982.

103) Goodall BL, Barnes DA, Benedikt GH, McIntosh LH (1996) Proceedings of the 6th International Business Forum on Specialty Polyolefins (SPO96). Scotland Business Research, pp. 123-142. 
104) Eychenne P, Perez E, Rico I, Bon M, Lattes A, Moisand A (1993) Colloid Polym. Sci 271: 1049-1054.

105) Puech L, Perez E, Rico-Lattes I, Bon M, Lattes A (1997) New J. Chem. 21: 1235-1242.

106) Puech L, Perez E, Rico-Lattes I, Bon M, Lattes A (2000) Coll. Surf. A 167: 123-130.

107) Chemtob A, Gilbert RG (2005) Macromolecules 38: 6796-6805.

108) Lipian J, Mimna RA, Fondran JC, Yandulov D, Shick RA, Goodall BL, Rhodes LF (2002) Macromolecules 35: 89698977.

109) Stubbs JM, Muscato LR, Sundberg DC (2005) Polym. Mat. Sci. Eng. 93: 884-885.

110) Skupov KM, Marella PR, Hobbs JL, McIntosh LH, Goodall BL, Claverie JP (2006) Macromolecules 39: 4279-4281.

111) Drent E, van Dijk R, van Ginkel R, van Oort B, Pugh RI (2002) Chem. Commun. 744-745.

112) Drent E, Budzelaar PHM (1996) Chem. Rev. 96: 663-681.

113) Sen A (1993) Acc. Chem. Res. 26: 303-310.

114) Abu-Surrah AS, Rieger B (1999) Topics Catal. 7 : 165-177.

115) Anonymous (2000) Chem. Eng. News 78 Feb 28:16.

116) Held A, Kolb L, Zuideveld MA, Thomann R, Mecking S, Schmid M, Pietruschka R, Lindner E, Sunjuk M, Khanfar M (2002) Macromolecules 35: 3342-3347.

117) Schmid M, Lindner E, Wald J, Förster M, Wegner P (2002) WO02/48238. Applicant: BASF AG.

118) Schmid M, Chowdhry MM, Distler D, Leyrer R (2004) WO2004/108782. Applicant: BASF AG.

119) Guyot A, Tauer K (1994) Adv. Polym. Sci. 111: 43-65.

120) Nalwa HS, Rohwer LS (eds) (2003) Handbook of Luminescence, Display Materials, and Devices. American Scientific Publishers, Stevenson Ranch.

121) Wilson LM (1997) Materials Science and Technology. In: Cahn, RW, Haasen P, Kramer EJ (eds) Processing of Polymers. Meijer EH (vol ed) vol. 18. Wiley-VCH, Weinheim, pp. 659-705.

122) Landfester K, Montenegro R, Scherf U, Guntner R, Asawapirom U, Patil S, Neher D, Kietzke T (2002) Adv. Mater. 14:651-655.

123) Landfester K, Antonietti M, Scherf U, Neher D (2003) Max-Planck-Gesellschaft: WO03/50147.

124) Shirakawa H, Louis EJ, MacDiarmid AG, Chiang CK, Heeger AJ (1977) Chem. Commun. 578-580.

125) Chiang CK, Druy MA, Gau CS, Heeger AJ, Louis EJ, MacDiarmid AG, Park YW, Shirakawa H (1978) J. Am. Chem. Soc. 100: 1013-1015.

126) Shirakawa H (2001) Angew. Chem. 113: 2642-2648.

127) Shirakawa H (2001) Angew. Chem. Int. Ed. 40: 2574-2580.

128) MacDiarmid AG (2001) Angew. Chem. 113: 2649-2659.

129) MacDiarmid AG (2001) Angew. Chem. Int. Ed. 40: 2581-2590.

130) Heeger AJ (2001) Angew. Chem. 113: 2660-2682.

131) Heeger AJ (2001) Angew. Chem. Int. Ed. 40: 2591-2611.

132) Sherman OA, Grubbs RH (2001) Synth. Metals 124: 431-434.

133) Huber J, Mecking S (2006) Angew. Chem. 118: 6462-6465.

134) Huber J, Mecking S (2006) Angew. Chem. Int. Ed. 45: 6314-6317.

135) Basescu N, Liu ZX, Moses D, Heeger AJ, Naarmann H, Theophilou N (1987) Nature 327: 403-405. 